\title{
Triaxial Simple Shear test: TxSS
}

\author{
Mourad Karray $^{1, *}$ and Mohamed Chekired $^{2}$ \\ ${ }^{1}$ Université de Sherbrooke, Civil Engineering Department, 2500 boulevard de l'Université, Canada \\ ${ }^{2}$ Institut de recherché d'Hydro-Québec, Varennes, Québec, Canada
}

\begin{abstract}
This paper presents a combined triaxial simple shear (TxSS) apparatus developed by the Research Institute of Hydro-Québec (IREQ) in collaboration with the soil dynamics and geotechnical engineering group of the Université de Sherbrooke (Québec, Canada). The TxSS system consists of a simple shear apparatus incorporated in a triaxial cell for the measurements of monotonic and dynamic characteristics of soil samples. A general description as well as some applications and advantages of the TxSS systems over the traditional apparatus are presented. The key application of the TxSS is the evaluation of liquefaction potential of soil under regular or irregular excitations. Test results in terms of monotonic and dynamic characteristics obtained using the TxSS device on different cohesive and cohesionless soil samples are presented to illustrate its capabilities. They are successfully compared to those obtained using reliable design charts available in the literature, conventional apparatus and to those from rigorous numerical analyses.
\end{abstract}

\section{Introduction}

It has been widely recognized among researchers and design engineers that laboratory tests that replicate field loading conditions as closely as possible should be performed to estimate the relevant geotechnical parameters in a design situation [e.g., 1, 2]. A wide variety of laboratory apparatuses are available, each with different merits and limitations with respect to different problems. For example, in conventional triaxial compression and extension tests, plane strain tests, and true triaxial tests, only normal stresses are controlled and measured. Triaxial equipment cannot duplicate rotations of the principal stress directions during shearing that are usually encountered in the field under earthquake loadings. In fact, conventional triaxial tests only allow for an instantaneous rotation through $90^{\circ}$ of the principal stress directions. The direct simple shear (DSS) test apparatuses are often superior to triaxial test devices as they allow for a smooth and continuous rotation of the principal stress directions during shearing. A major limitation of the DSS test appears to be the practical difficulty of imposing a uniform normal and shear stress field along the plane of deformation. The DSS devices do not allow for the development of complementary shear stresses on the vertical sides normal to the plane of deformation, and consequently the shear and normal stresses must be non-uniform along the plane of deformation [3]. Moreover, many in situ conditions of soils are 3-dimensional in nature and cannot always be simplified to the unidirectional loading conditions that are modelled in the DSS test apparatuses [e.g., 1, 2, 4, 5].

To provide reliable results, the device used should meet certain requirements including [e.g., 2, 6]: (i) the ease of mounting reconstituted and undisturbed soil samples; (ii) the facility to consolidate a soil specimen under drained conditions to a desirable confining pressure, and then sheared under either drained or undrained conditions; (iii) the opportunity to apply back pressure to ensure full saturation of the specimen and the direct measurement of the pore water pressure during the undrained shear test; (iv) the ability to rotate principle stresses of the tested specimen; and (v) the ability to utilize a sample large enough to develop a well-defined failure zone.

In an attempt to make consummate investigations (i.e., obtain high quality experimental test data) of the static and dynamic characteristics of soil samples in a triaxial condition, a new combined triaxial simple shear (TxSS) apparatus was designed and build to achieve simple shear stressing on a soil sample in a triaxial chamber. The device is operated by an electric system which is capable of varying both shearing and confining stresses on a cylindrical soil specimen either monotonically or cyclically at different stress amplitudes and frequencies up to $10 \mathrm{~Hz}$. The apparatus also offers the opportunity to apply regular and irregular cyclic strain or stress on the soil sample. The TxSS can be reduced to the DSS by using stacks of annular plates to laterally support the soil specimen or to the conventional triaxial test if there is no shear loading applied. A general description as well as some advantages and applications of the developed TxSS system are given in the subsequent sections. Sample results showing the static and dynamic characteristics obtained using the TxSS device on different cohesive and cohesionless soil samples are presented to illustrate its capabilities. They are compared to those obtained using design charts available in the literature and to those calculated with numerical analyses using the computer code FLAC [7]

\footnotetext{
* Corresponding author: mourad.karray@,usherbrooke.ca
} 


\section{The triaxial simple shear (TxSS) apparatus}

The TxSS apparatus was designed and manufactured to permit the application of monotonic loading as well as both regular and irregular shear stresses or strains to soil specimens. Figure 1 shows the general assembly of the TxSS apparatus. The TxSS device was designed to test cylindrical soil specimens with a diameter of $63 \mathrm{~mm}$ or 80 $\mathrm{mm}$ and varying heights in a triaxial pressure cell so that confining pressure and back pressure can be applied and monitored. The specimen is located between relatively rigid bottom and top caps and is typically confined by a rubber membrane. The bottom and top caps that contain fine porous stones provide a "frictional" surface while allowing for drainage. The specimen is first consolidated to a desirable confining stress, and then simple shear stress or strain is presumed to be imposed by displacing the specimen top cap using the shear ram shown in Fig. 1, which is connected to a shaker mounted on a rigid horizontal table. A computer-automated feedback-loopcontrolled system provides an excellent control of stresses and strains. The TxSS system permits testing soil samples with different heights under either drained or undrained conditions as well as the direct measurement of the pore water pressure generation during undrained shear tests. It also provides the opportunity for geotechnical engineers and researchers to test undisturbed and reconstituted soil samples under either isotropic or anisotropic loading conditions. Unlike the DSS test apparatus that limits the height of soil specimen to ensure uniform strain distribution in the specimen, the TxSS test can be performed for various specimen heights. Well-defined failure zone such as the one shown in Fig. 2a can also be observed under unidirectional shearing which is consistent with the failure pattern soils typically experience in many practical geotechnical situations.

As mentioned in the introduction, the TxSS can also reproduce the DSS if the soil sample, prepared in a membrane-enclosed space, is surrounded by stacks of annular plates (rings), and if a zero-confining pressure is applied (Fig. 2b). A new reinforcement method was also developed using fiberglass tape as shown in Fig. 2c. This method appears effective to confine the soil sample laterally without the need of specialized equipment as in the case of the armed membranes with iron wires. The TxSS may also be reduced to the conventional triaxial test if there is no shear stress or strain applied on the top cap.

\section{TxSS results}

To evaluate the TxSS device performance, a series of monotonic, cyclic and seismic tests on different types of cohesive and cohesionless soils were performed and the obtained results are then compared to those obtained using reliable design charts available in the literature as well as those from numerical analyses using FLAC [7].

\subsection{Properties of the tested soils}

The granular soils used in this study are Baie-Saint-Paul

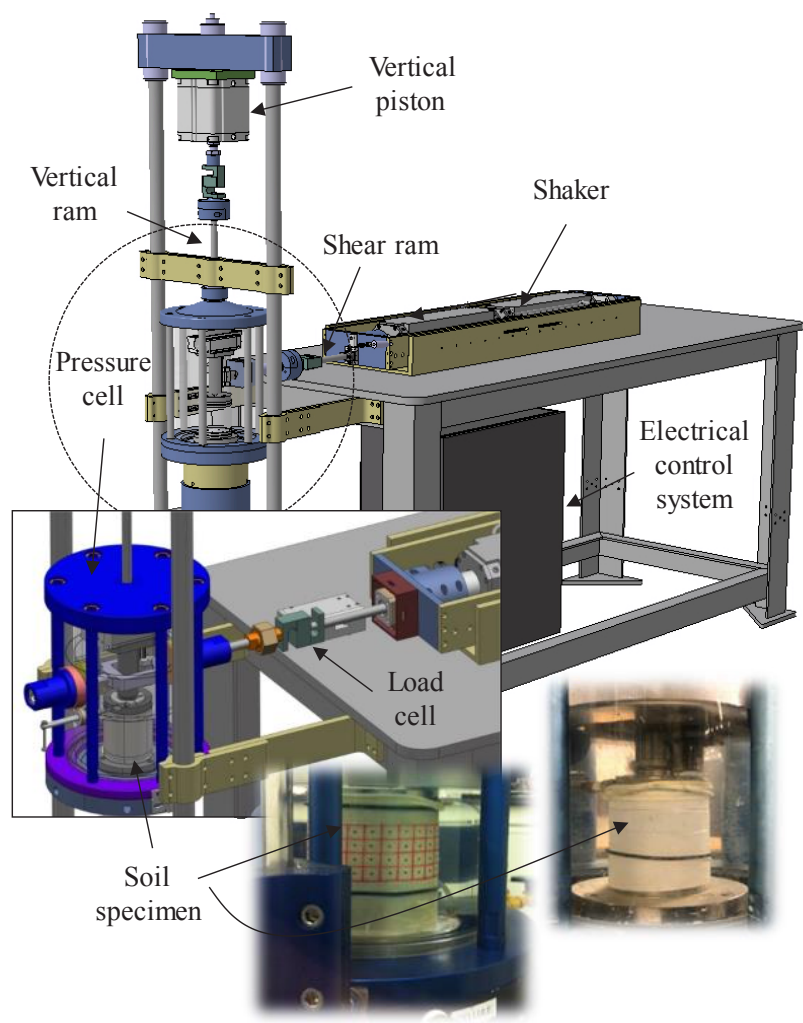

Fig. 1. Schematic sketch of the triaxial simple shear (TxSS) apparatus.
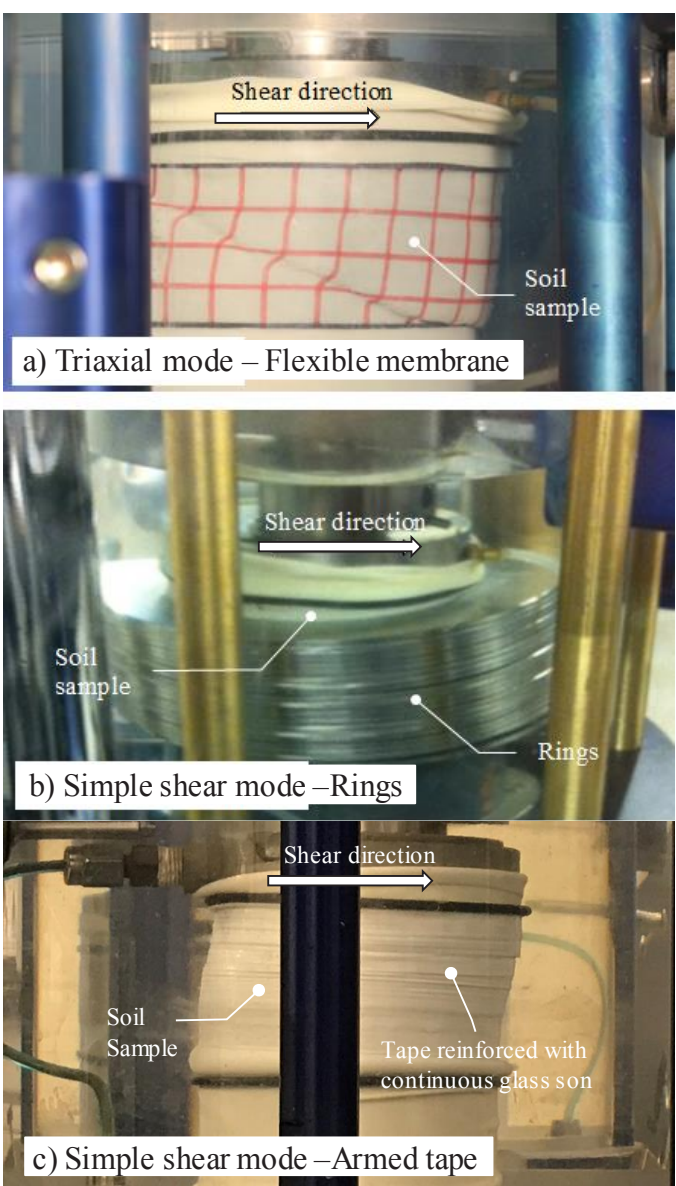

Fig. 2 Different types of reinforcement and modes of shearing using the $\mathrm{T}_{\mathrm{x}} \mathrm{SS}$. 

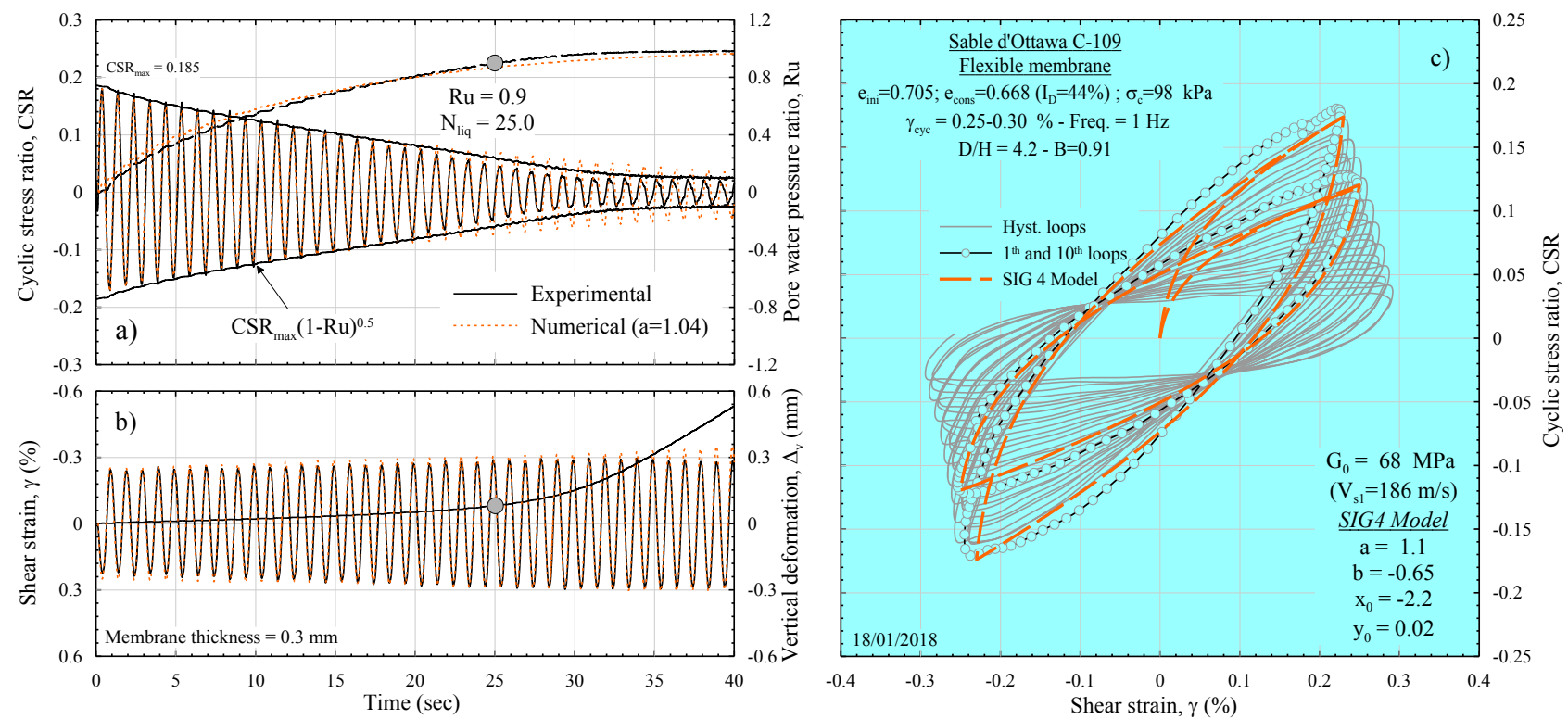

Fig. 3. Time histories of cyclic stress ratio, excess pore pressure and hysteresis loops of an Ottawa sand C-109 tested at a $100 \mathrm{kPa}$ confining pressure and a relative density of $40 \%$ under cyclic strain $\gamma_{\mathrm{cyc}}=0.25 \%$ and a frequency $=1 \mathrm{~Hz}$.

and Ottawa C-109 sands. The physical properties of these soils are presented in Table 1. The cohesive soil used is a post-glacial clay coming from a site near Québec City (Québec, Canada).

Table 1: Physical properties of the C-109 Ottawa sand

\begin{tabular}{lcc}
\hline $\begin{array}{l}\text { Soil } \\
\text { properties }\end{array}$ & $\begin{array}{c}\text { Baie-Saint-Paul } \\
\text { sand }\end{array}$ & $\begin{array}{c}\text { Ottawa sand } \\
\text { C-109 }\end{array}$ \\
\hline $\mathrm{G}_{\mathrm{s}}$ & 2.78 & 2.67 \\
$\mathrm{e}_{\max }$ & 0.91 & 0.82 \\
$\mathrm{e}_{\min }$ & 0.598 & 0.5 \\
$\mathrm{C}_{\mathrm{u}}$ & 2.25 & 1.75 \\
$\mathrm{C}_{\mathrm{c}}$ & 1 & 1.016 \\
$\mathrm{D}_{50}$ & 0.15 & 0.37 \\
\hline
\end{tabular}

\subsection{Cyclic loading response}

The cyclic triaxial simple shear test (TxSS) apparatus was designed to provide confining pressure to the soil specimen during simple shearing applied by regular or irregular waveforms. Baie-Saint-Paul samples obtained from the Couvant de Baie-Saint-Paul (Québec, Canada) site and a calibrated Ottawa sand C-109 were used in this study with their properties summarized in Table 1 . Wet tamped preparation method was used to reconstitute soil specimens in a rubber membrane. The specimens were 80 $\mathrm{mm}$ in diameter and $26 \mathrm{~mm}$ in height. Moist sand was placed in three layers and every layer compacted to the desired density. After saturation, with a Skempton's B value greater than 0.97 , the sample was isotropically consolidated to an initial stress ratio of $\mathrm{K}_{0}=\left(\sigma_{\mathrm{h}}^{\prime} / \sigma_{\mathrm{v}}^{\prime}\right)=1$, where $\sigma_{v}^{\prime}$ and $\sigma_{h}^{\prime}$ are the effective vertical and horizontal stresses, respectively. After consolidation, the specimens were subjected to cyclic shear strain under undrained condition until initial liquefaction occurred. Initial liquefaction is defined throughout this study when the excess pore pressure, $R u=u / \sigma_{c o}^{\prime}$, reaches a value of 0.9 , where $u$ is the residual pore pressure; $\sigma_{c o}^{\prime}$ is the initial confining pressure.
A series of undrained cyclic strain-controlled tests on Ottawa C-109 and Baie-Saint-Paul sands under isotropic stress conditions and at different values of $\gamma_{\mathrm{cyc}}$ was conducted until initial liquefaction occurred. The sample preparation method and the testing procedure mentioned above were almost the same in all tests. All tests have been carried out at the initial effective confining pressure of $100 \mathrm{kPa}$ and $75 \mathrm{kPa}$ for Ottawa C-109 and Baie-SaintPaul sands, respectively, and at the same loading frequency of $1 \mathrm{~Hz}$. A typical response of the Ottawa C109 sand to cyclic loading is presented in Figs. 3a-c. In particular, Fig. 3a shows that the reduction in shear stiffness of the soil due to the cyclic shear strain is associated with a very small increase in the vertical deformation of soil structure $\varepsilon_{\mathrm{v}}$ (Fig. 3b) until liquefaction $(\mathrm{Ru}=0.9)$. Figure $3 \mathrm{a}$ also shows the pore pressure built up as the loading progresses. Figure $3 \mathrm{a}$ indicates that the soil is liquefied after 25 cycles. Figure $3 \mathrm{a}$ also shows that the increase of the excess pore pressure, $\mathrm{Ru}$, with strain cycles results in exponential decay of cyclic stress ratio (CSR). Where, CSR is defined as the amplitude of the applied cyclic shear stress $\left(\tau_{\text {cyc }}\right)$ divided by the initial effective confining stress $\left(\sigma_{\mathrm{co}}^{\prime}\right)$. Figure $3 \mathrm{c}$ shows the variation of CSR with the applied cyclic shear strain. It is important to note from Figs. 3c, that the CSR- $\gamma_{\text {cyc }}$ hysteresis loops rotate toward the $\gamma$ axis with the increase in the number of cycles, and the bounded area representing the dissipated energy decreases with further cycles.

\subsection{Comparison with DSS and literature}

\subsubsection{Energy concept}

The strain controlled TxSS tests results can be used to build robust constitutive models thanks to the energybased concept. Energy-based pore pressure models typically relate the ratio of excess pore pressure generated during shearing to the normalized unit energy $\left(\mathrm{W}_{\mathrm{s}}\right)$, that can be defined as the energy dissipated per unit volume of soil divided by the initial effective confining pressure [8]. 
The dissipated energy for a soil sample in cyclic loading can be determined by integrating the area bounded by the stress-strain hysteresis loops (Fig. 3c), as suggested by [9]. The energy dissipated per unit volume of soil divided by the initial effective confining pressure for different TxSS tests on samples of Baie-Saint-Paul and Ottawa C109 sands tested under different applied shear strains are correlated against the excess pore pressure generated through the following equations, respectively:

$$
\begin{gathered}
\mathrm{Ru}=\left(\frac{W_{\mathrm{s}}^{0.5}}{\mathrm{a}=0.87 \gamma_{\mathrm{cyc}}^{-0.8}}\right)^{1.327} \\
\mathrm{Ru}=0.95\left(\frac{W_{\mathrm{s}}^{0.5}}{\mathrm{a}=0.54 \gamma_{\mathrm{cyc}}^{-0.44}}\right)^{1.145}
\end{gathered}
$$

For a given soil, the calibration parameter, a, is a function of the strain level and greatly depends on the relative density. The value of an increases with the increasing of density. The performance of the energy-based procedure represented in Eqs. 1 and 2 is examined against the experimental data from the TxSS tests on Ottawa and Bais-Saint-Paul sands using regular and irregular loading. The computer code FLAC [7] is employed to simulate the TxSS tests. The functions that determine the variation of the pore pressure during excitation may therefore be integrated into a dynamic response analysis through a constitutive model properly describing the hysteresis stress-strain behaviour of the soil. It is then possible to simulate the induced $\mathrm{Ru}$ for any given soil for a regular cyclic stress loading or any seismic loading and assess its potential liquefaction hazard.

\subsubsection{Ottawa C-109 sand - cyclic loading}

The hysteresis behaviour of soils can be modelled using FLAC. The sigmoidal SIG4 model in FLAC is adjusted to the TxSS test results of the C-109 Ottawa sand to represent their hysteretic behaviour as shown in Fig. 3c. It should be noted that the evaluation of the pore pressure in each hysteretic loop allows adjusting progressively the effective stress $\left(\sigma^{\prime}=\sigma_{c}(1-R u)\right)$ and thus reduces the shear modulus according to the following:

$$
G_{\max }=G_{\max -i n i}(1-R u)^{0.5}
$$

The constitutive model used automatically accounts for the shear modulus G. Hence, the soil resistance calculation is performed with effective stresses.

The performance of the energy-based procedure previously described is examined against the straincontrolled experimental data from the TxSS tests on Ottawa C-109 sand, as shown in Fig. 3. Fig. 3a indicates that there is an excellent agreement between the measured and the computed excess pore pressures $(\mathrm{Ru})$ and cyclic stress ratios (CSR). Then, it is possible to deduce the number of cycles required to reach $\mathrm{Ru}$ of 0.9 by applying a cyclic shear stress of $\tau_{\text {cyc }}$ (stress-controlled). Figure 4 shows the computed cyclic resistance ratio (CRR) against the number of cycles for the Ottawa C-109 sand at $\mathrm{I}_{\mathrm{D}}=40 \%$. Fig. 4 also presents the results of DSS tests conducted on the same $\mathrm{C}-109$ sand at the same relative density using simple shear apparatus manufactured by
GDS Instruments (EMDCSS). The results obtained by [10] and corrected for the confining stress using the relations proposed by and [11] are also shown in Fig.4. Both the DSS tests and the results from the literature show that the TxSS simulates properly the cyclic resistance of the soil under cyclic loading. The stress-path of Ottawa Sand C-109 tested in the TxSS apparatus under monotonic loading is compared in Fig. 5 to the cyclic stress path obtained by applying the strain established using numerical simulations for a $\mathrm{CSR}=0.125$. These results indicate high coherence between the numerical and TxSS results and between monotonic and cyclic results.

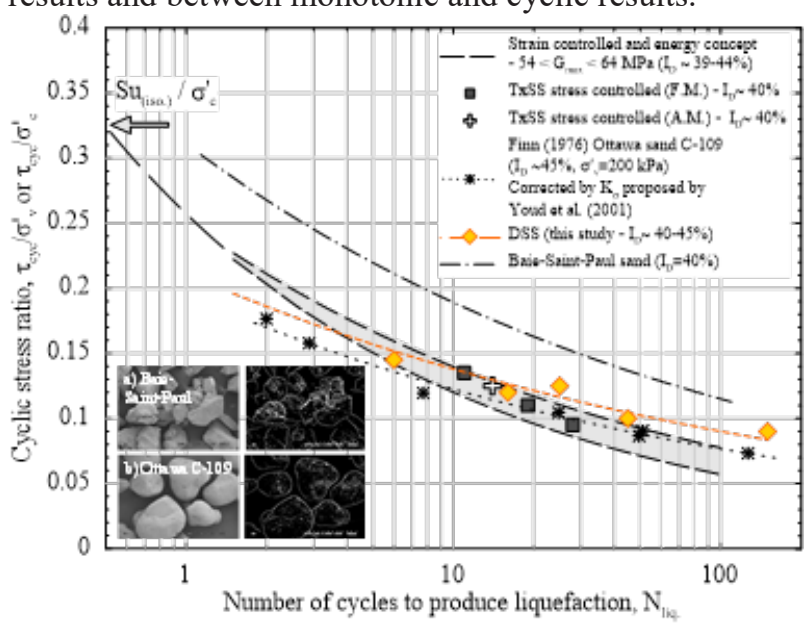

Fig. 4 Comparison between sand CSR-N liq chart obtained from TxSS strain controlled tests and energy concept with DSS and [10] stress-controlled results.

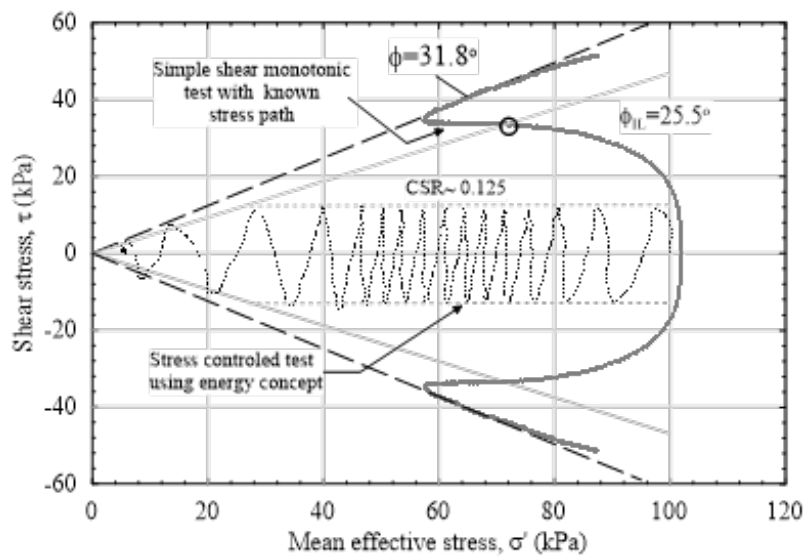

Fig. 5 Ottawa C-109 stress-paths of monotonic and stress-controlled TxSS tests

The cyclic resistance, CRR, determined for the BaieSaint-Paul sand using the TxSS tests and the energy concept is also shown in Figure 4. This resistance is about $33 \%$ higher than that of the Ottawa sand C-109 for approximately the same relative density $\left(\mathrm{I}_{\mathrm{D}} \approx 40 \%\right)$. Several studies $[12,13]$ indicate that particle shape plays an important role in the cyclic resistance of sands. Figure 4 actually shows a large difference in terms of shape between the two sands and it appears that the more rounded the soil particles are, the lower the resistance to liquefaction.

\subsubsection{Baie-Saint-Paul sand - seismic loading}


As indicated earlier, the TxSS apparatus can be used to examine the soil response to real earthquake and this may be of furthermost importance in evaluating liquefaction potential of soil deposit as discussed in the following example. The computer code FLAC and the constitutive model established by equation 1 are used to analyse the seismic response of the Baie-Saint-Paul deposit located at Baie-Saint-Paul site (Québec) and extended to a depth of $250 \mathrm{~m}$. More details about the site and the in situ measurements conducted can be found in [14]. A synthetic earthquake record, recommended by [15] and compatible with the spectrum for Baie-Saint-Paul site (class A) [16], was used to evaluate the seismic response of the soil deposit (Fig. 6a).

Figure 6 shows a comparison between the measured and the computed response of Baie-Saint-Paul sand under the action of the compatible seismic signal. In Fig. $6 \mathrm{~b}$ the computed shear strains at a depth of 7-8 $\mathrm{m}\left(\sigma^{\prime}{ }_{\mathrm{c}}\right.$ of $\left.75 \mathrm{kPa}\right)$ from the ground surface using FLAC are applied to the Baie-Saint-Paul sand sample in the TxSS apparatus under the same confining pressure. The measured time histories of the excess pore pressure $(\mathrm{Ru})$ as well as the cyclic stress ratio (CSR) are compared to the computed time histories in Figs 6d and 6c, respectively. The results shown in Fig. 6 indicate that the measured and the computed responses in terms of $\mathrm{Ru}$ and CSR are very similar. This similarity confirms the accuracy and reliability of the TxSS test results and of the energy-based model adopted.

The measured CSR using Seed's and his colleagues equivalent uniform cycle concept proposed by [17] is about 0.182 (Fig. 6c). The soil is fully liquefied due to the action of the compatible record (Fig. 6d) after $9 \mathrm{sec}$. The number of equivalent uniform cycles calculated from Fig. $6 \mathrm{c}$ is about 8 to 9 . This number of cycles corresponds well with the one calculated from TxSS strain-controlled tests and energy concept (Fig. 4). The coherence between the results shows clearly that the TxSS simulator can be used to simulate the effect of earthquake on soil behaviour. The new method proposed in this study can be applied directly to earthquakes compatible with those of Eastern Canada and to see the evolution of excess pore pressures in the desired layers. In this case, it is no longer necessary to transform the irregular cycles to an equivalent regular ones and counting the number of cycles. Overall, the new assessment procedure eliminates much of the uncertainty related to the compatibility of the seismic excitations.

\subsection{G/Gmax degradation and damping curves}

The TxSS apparatus offers the ability to determine the soil stiffness over a wide range of strain spectrum from $0.001 \%$ to $10 \%$. The motor is characterized by its highthrust capability (up to $100,000 \mathrm{~N}$ ), its high precision $(0.07 \mathrm{~nm})$, and its very low speed fluctuation $( \pm 0.006 \%$ at $100 \mathrm{~mm} / \mathrm{s}$ ). It is very quit due to the absence of friction. The max. and min. speed drive are $10 \mathrm{~m} / \mathrm{s}$ and $\mu 8 \mathrm{~m} / \mathrm{s}$, respectively. A computer-automated feedback-loopcontrolled system provides an excellent control of stresses and strains.

A PA-Québec clay extracted from a depth of $27 \mathrm{~m}$ of $\mathrm{PI}$ equal to 7 and a sensitivity $\mathrm{St}=4$ was consolidated under a confining pressure of $200 \mathrm{kPa}(\mathrm{OCR}=1.6)$. Once the consolidation is completed, the drainage line was closed and the specimen was cyclically sheared under
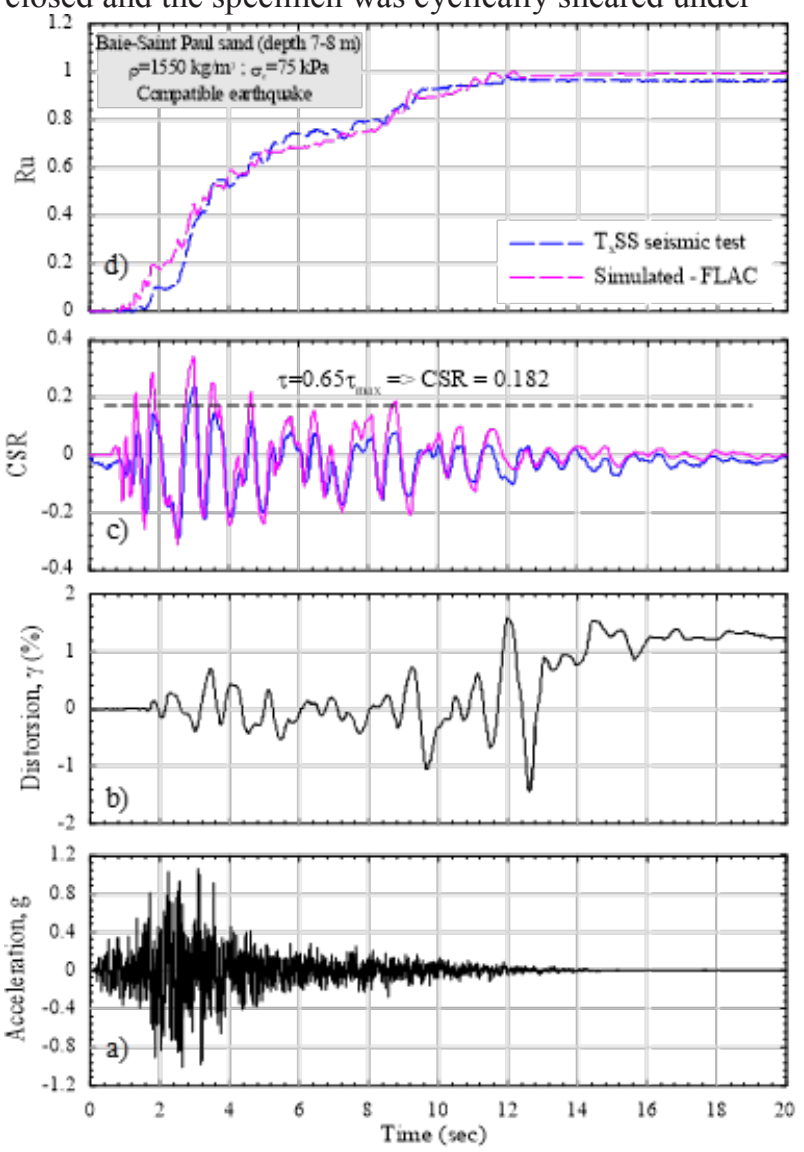

Fig. 6. Measured and computed response of BaieSaint-Paul sand to a compatible record with [16].

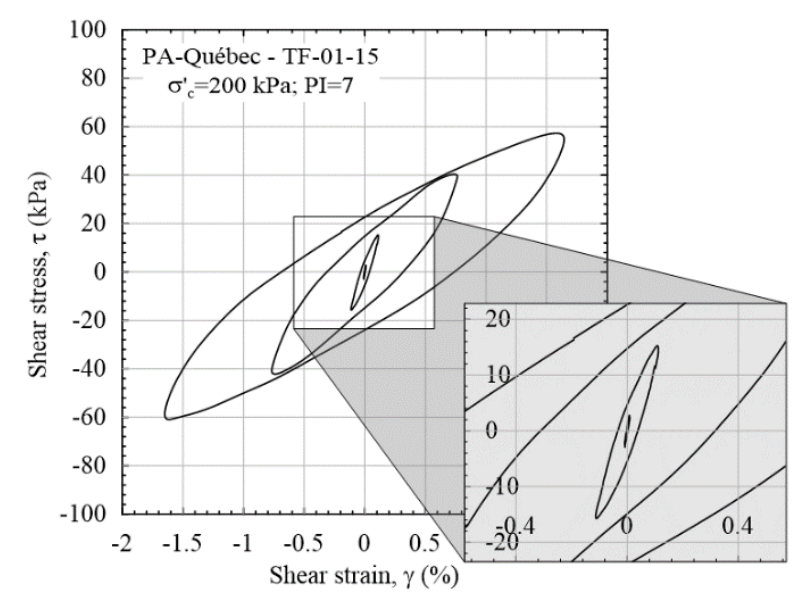

Fig.7 Examples of loops at small and large strain obtained with the new TxSS apparatus

strain-controlled condition with a maximum shear strain of $1.7 \%$ and a frequency of $1 \mathrm{~Hz}$. Each plot in Fig. 7 shows a shear stress-shear strain loop observed at different cyclic strain levels (0.001-1.7\%). Each loop in Fig. 7 is in fact an average of 6 cycles applied to the specimen at the same max. strain amplitude. As shown in Fig. 7, a gradual increase in the loop area is observed with the increase in the applied cyclic shear strain. Figure 8 shows the variation of the normalized shear modulus $\left(\mathrm{G} / \mathrm{G}_{\max }\right)$ and damping ratio (D) with shear strain, obtained from the TxSS. G/Gmax degradation and damping curves 
suggested by [18] for clays with PI $=0$ and by [19] for $\mathrm{PI}=9$ are plotted in Fig. 8 for comparison. The experimental G/Gmax and damping data generally fall within the range suggested by [19].
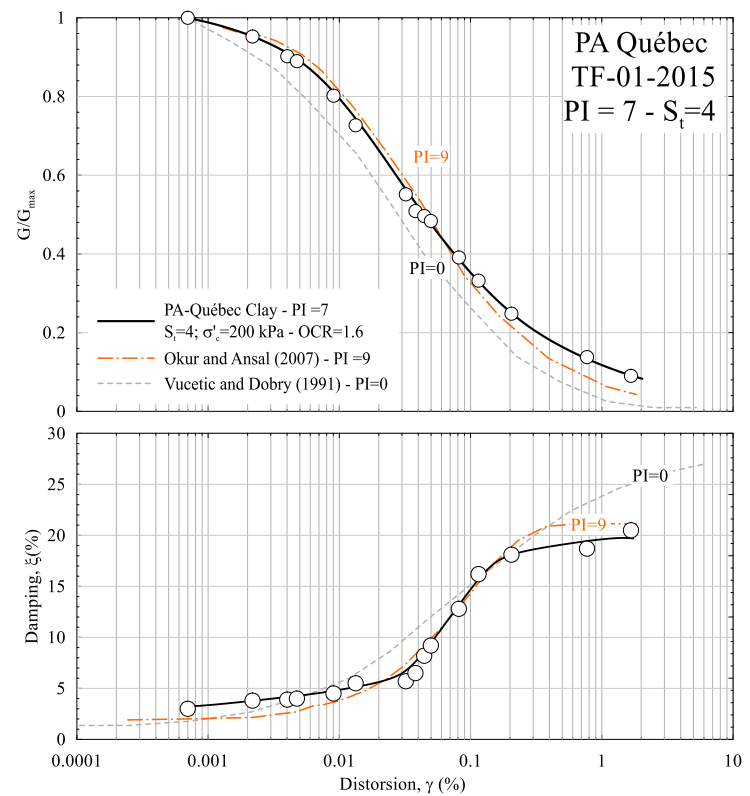

Fig 8. Shear stiffness and damping vs shear strain

\section{Conclusion}

A wide variety of laboratory apparatuses such as triaxial, direct simple shear, and ring shear devices are available to evaluate the static and dynamic responses of cohesive and cohesionless soils. However, most of these techniques have their limitations such as the inability to rotate principle stresses; inability to simulate the threedimensional in situ conditions of soils; the inability to apply confining pressure to the soil samples and incapacity to construct the $\mathrm{G} / \mathrm{G}_{\max }$ degradation curve with the same apparatus. Aware of these limitations, a new combined triaxial simple shear (TxSS) apparatus that minimizes their impacts has been designed and constructed in the course of a collaboration project between Hydro-Québec and Université de Sherbrooke. The TxSS system consists of a simple shear apparatus incorporated in a triaxial cell for the measurements of static and dynamic characteristics of soil samples. Comparative TxSS tests on different cohesive and cohesionless soil samples and numerical analyses using the code FLAC demonstrate the capabilities of the new apparatus to obtain high quality experimental test data. As demonstrated, the experimental data obtained with the TxSS agree with many established geotechnical design charts found in the literature.

\section{References}

1. Dyvik, R., Berre, T., Lacasse, S., and Raadim, B. (1987). Comparison of truly undrained and constant volume direct simple shear tests. Géotechnique, 37(1): 3 -10.

2. Boulanger, R. W., Chan, C. K., Seed, H. B., and Seed, R. B. (1993). A low-compliance bi-directional cyclic simple shear apparatus. Geotechnical Testing Journal, 16(1): 36 - 45.
3. Airey, A, Budhu, M, and Wood, D. M. (1985). The behaviour of soils in simple shear. In Developments in soil mechanics and foundation engineering. 2. Edited by P. K. Banerjee and R. Butterfield. Applied Science Publishers, London, United Kingdom, 185 - 213.

4. Franke, E., Kiekbusch, M., and Schuppener, B. (1979). A new direct simple shear device. Geotechnical Testing Journal, 2(4): 190 - 199.

5. Duku, P.M., Stewart, J. P, Whang, D. H, and Venugopal, R. (2007). Digitally controlled simple shear apparatus for dynamic soil testing. Geot. Testing Journal, 30(5): 1 - 10.

6. Sadrekarimi, A. and Olson, S. M. (2009). A new ring shear device to measure the large displacement shearing behaviour of sands. Geot. Testing Journal, ASTM, 32(3): 1 - 12.

7. Itasca Consulting Group, FLAC. (2010). Fast lagrangian analysis of continua in 2-dimensions 6.0, manual. Itasca, Minneapolis.

8. Polito, C., Green, R. A., Dillon, E., Sohn, C. (2013). Effect of load shape on relationship between dissipated energy and residual excess pore pressure generation in cyclic triaxial tests. Canadian Geotechnical Journal, 50(11): 1118-1128.

9. Green, R. A., Mitchell, J. K., and Polito, C. P. (2000). An energy-based pore pressure generation model for cohesionless soils. In Proceedings of the John Booker Memorial Symposium-Developments in Theoretical Geomechanics, 16-17. Balkema, Rotterdam, the Netherlands. 383-390.

10. Finn, W. D. L., "Liquefaction Potential: Developments Since 1976," Proceedings of the International Conference on Recent Advances in Geotechnical Earthquake Engineering and Soil Dynamics, University of Missouri, Rolla, Missouri, 1981.

11. Youd, T.L., et al. (2001). Liquefaction resistance of soils. Summary report from the 1996 NCEER and 1998 NCEER/NSF workshops on evaluation of liquefaction resistance of soils. Journal of Geotechnical and Geoenvironmental Engineering, 127(10): 817-33.

12. Ishibashi M. A. Sherif W. L. Cheng (1981). Effect of Material Properties on Soil Liquefaction I.

13. Y. P. Vaid, J. M. Fisher; R. H. Kuerbis; D. Negussey Particle Gradation and Liquefaction, Journal of Geotechnical Engineering Volume 116 Issue 4 - April 1990

14. Karray, M., Lefebvre, G. and Ethier, Y. (2011). Relevés MMASW et évaluation du potentiel de liquéfaction au site du couvent de Baie-Saint-Paul. Technical report for Les Petites Franciscaines de Marie, Géowave Inc., Sherbrooke, Québec, Canada, p. 78.

15. Atkinson, G. M. (2009). Earthquake time histories compatible with the 2005 National building code of Canada uniform hazard spectrum. Canadian Journal of Civil Engineering, 36(6): 991-1000.

16. National Building Code of Canada (2015). National Research Council, Ottawa.

17. Seed, H.B., Idriss, I.M., Makdisi, F., and Banerjee, N. (1975). Representation of irregular stress time histories by equivalent uniform stress series in liquefaction analysis. Report No. EERC 75-29, Earthquake Engineering Research Center, College of Engineering, Univ. of California, Berkeley, California, United States.

18. Vucetic, M. and Dobry, R. (1991). Effect of soil plasticity on cyclic response. Journal Geotechnical Engineering, 117(1): 89 - 107.

19. Okur, D.V., Ansal, A. (2007) Stiffness degradation of natural fine grained soils during cyclic loading. Soil Dynamics and Earthquake Engineering 27: 843-854. 